\title{
Haemodynamics in children during rest and exercise: methods and normal values
}

\author{
M. Rosenthal, A. Bush
}

Haemodynamics in children during rest and exercise: methods and normal values. $M$. Rosenthal, A. Bush. (OERS Journals Ltd 1998.

ABSTRACT: Measuring haemodynamic performance in children is either invasive, and thus unacceptable, or noninvasive when the measured variable is often remote from the true variable. Measuring only maximum performance variables relies too heavily on motivation, especially in disease groups. We describe a method for the measurement of haemodynamic performance using respiratory mass spectrometry during rest, exercise and recovery therefrom.

One hundred and six healthy children ( 55 male, 51 female) aged 8-16.9 yrs underwent an identical exercise protocol. Following studies at rest, they initially bicycled at $25 \mathrm{~W} \cdot \mathrm{m}^{-2}$, increasing every $3 \mathrm{~min}$ by $15 \mathrm{~W} \cdot \mathrm{m}^{-2}$ until exhaustion, after which measurements were made during recovery. Effective pulmonary blood flow, stroke volume, oxygen consumption, arteriovenous oxygen difference and functional residual capacity (FRC) together with estimates of pulmonary capillary blood volume and transit time were assessed at every exercise stage using inert gas rebreathing techniques.

Haemodynamic performance is highly dependent on surface area, age, gender and pubertal stage. Many parameters, for example transfer factor, demonstrate pubertal stage-dependent differences at identical workloads even after correction for size. Females have a lower capillary blood volume at rest compared to age and sizematched males, but it is equalized during exercise. FRC unexpectedly rose with exercise, and peak exercise was associated with a falling stroke volume in $91 \%$ (95\% CI 84-96\%) of children, a possible demonstration of Starling's law of the heart. Oxygen pulse (oxygen consumption/cardiac frequency) is a very poor marker for pulmonary blood flow.

Normal values are provided for all haemodynamic parameters for rest and every exercise stage for all subgroups of children. This should allow accurate comparison of normal and disease groups in future.

Eur Respir J 1998; 11: 854-865.
Dept of Paediatric Respiratory Medicine, The Royal Brompton Hospital, London, UK.

Correspondence: M. Rosenthal

Dept of Paediatric Respiratory Medicine

The Royal Brompton Hospital

London SW3 6NP

UK

Fax: 441713518763

Keywords: Children

exercise

haemodynamics

mass spectrometry

normal values

Received: July 301997

Accepted after revision December 151997

This study was in part funded by Innovision PLC, Denmark.
Innumerable papers describe values for cardiopulmonary variables in children during rest and exercise using a wide variety of protocols and these have been summarized by JAMES et al. [1]. The majority measure cardiac frequency $(f \mathrm{C})$, oxygen consumption $\left(V^{\prime} \mathrm{O}_{2}\right)$, carbon dioxide production $\left(V^{\prime} \mathrm{CO}_{2}\right)$, and respiratory frequency $(f \mathrm{R})$ with standards quoted for peak $V^{\prime} \mathrm{O}_{2}, f \mathrm{C}$, anaerobic threshold and ventilatory threshold. From these surrogate markers, inferences are often made about cardiac performance. There are few direct catheter measurements of cardiac output $\left(\bar{Q}^{\prime}\right)$ in healthy children [2-4]. Catheterization is nowadays unacceptable in healthy children and the data collected under such a stress bear little resemblance to normal life. Noninvasive measures of effective pulmonary blood ( $Q^{\prime}$ 'eff) flow are only available in resting children [5], but during exercise a $Q^{\prime}$ eff $/ V^{\prime} \mathrm{O}_{2}$ linear equation is frequently used $[6,7]$. Such a linear relationship is unlikely [8]. There are few paediatric data on stroke volume, and none concerning gas transfer during exercise. There is little data on how children recover from exercise.

It is doubtful whether normal values of variables at "maximum" exercise are useful as the concept of a maxi- mum will depend on the motivation of the child and the exercise protocol rather than some physiological plateau. It is, therefore, desirable to know haemodynamic performance at defined submaximal levels of exercise so that comparison between normals and disease groups is possible, regardless of motivation.

We therefore present a method for the simultaneous assessment of cardiopulmonary haemodynamics using noninvasive respiratory mass spectrometry during rest, exercise and recovery.

\section{Methods}

The study received approval from the Royal Brompton Hospital ethics committee and informed, written consent was obtained from all parents and children.

\section{The study population}

One hundred and six healthy children (55 male, $51 \mathrm{fe}-$ male) were recruited from the three London state schools closest to the study venue. Two hundred and thirty nine 
Table 1. - Growth variables for each subgroup of children together with numbers of children completing a particular workload, their group median maximum workload and group lower limit of normality

\begin{tabular}{|c|c|c|c|c|c|c|c|c|}
\hline \multirow{3}{*}{ Growth variables } & \multicolumn{8}{|c|}{ Age group yrs } \\
\hline & \multicolumn{2}{|c|}{ д10.50 } & \multicolumn{2}{|c|}{$10.51-12.50$} & \multicolumn{2}{|c|}{$12.51-14.50$} & \multicolumn{2}{|c|}{$>14.50$} \\
\hline & M & $\mathrm{F}$ & $\mathrm{M}$ & $\mathrm{F}$ & M & $\mathrm{F}$ & M & $\mathrm{F}$ \\
\hline Subjects $n$ & 11 & 12 & 13 & 11 & 18 & 19 & 13 & 9 \\
\hline Height $\mathrm{cm}$ & $\begin{array}{c}137 \\
(129-151)\end{array}$ & $\begin{array}{c}139 \\
(129-147)\end{array}$ & $\begin{array}{c}150 \\
(144-164)\end{array}$ & $\begin{array}{c}152 \\
(142-163)\end{array}$ & $\begin{array}{c}160 \\
(144-174)\end{array}$ & $\begin{array}{c}157 \\
(145-170)\end{array}$ & $\begin{array}{c}173 \\
(167-183)\end{array}$ & $\begin{array}{c}162 \\
(148-167)\end{array}$ \\
\hline Height z-score & $\begin{array}{c}0.23 \\
(-1.0-3.0)\end{array}$ & $\begin{array}{c}1.22 \\
(-1.2-2.3)\end{array}$ & $\begin{array}{c}0.79 \\
(-0.4-2.5)\end{array}$ & $\begin{array}{c}0.53 \\
(-0.2-1.6)\end{array}$ & $\begin{array}{c}0.07 \\
(-1.7-1.9)\end{array}$ & $\begin{array}{c}-0.1 \\
(-1.6-1.8)\end{array}$ & $\begin{array}{c}0.27 \\
(-0.6-1.9)\end{array}$ & $\begin{array}{c}-0.1 \\
(-0.2-0.9)\end{array}$ \\
\hline Weight $\mathrm{kg}$ & $36(23-57)$ & $32(23-46)$ & $41(37-68)$ & $44(33-61)$ & $52(36-61)$ & $48(31-65)$ & $62(51-75)$ & $52(44-66)$ \\
\hline Surface area $\mathrm{m}^{2}$ & $\begin{array}{l}1.16 \\
(0.9-1.5)\end{array}$ & $\begin{array}{c}1.12 \\
(0.9-1.4)\end{array}$ & $\begin{array}{c}1.33 \\
(1.2-1.8)\end{array}$ & $\begin{array}{c}1.37 \\
(1.1-1.7)\end{array}$ & $\begin{array}{c}1.54 \\
(1.2-1.7)\end{array}$ & $\begin{array}{c}1.49 \\
(1.1-1.7)\end{array}$ & $\begin{array}{c}1.71 \\
(1.5-1.9)\end{array}$ & $\begin{array}{c}1.53 \\
(1.4-1.7)\end{array}$ \\
\hline Triceps skinfold z-score & $\begin{array}{l}1.16 \\
(0.5-2.8)\end{array}$ & $\begin{array}{c}1.21 \\
(-0.9-2.8)\end{array}$ & $\begin{array}{c}1.25 \\
(-0.4-2.3)\end{array}$ & $\begin{array}{c}1.06 \\
(0.1-2.3)\end{array}$ & $\begin{array}{c}0.69 \\
(-1.0-2.4)\end{array}$ & $\begin{array}{c}0.82 \\
(-1.3-2.1)\end{array}$ & $\begin{array}{c}0.72 \\
(-0.9-1.9)\end{array}$ & $\begin{array}{c}0.83 \\
(-1.2-2.4)\end{array}$ \\
\hline Subscapular skinfold z-score & $\begin{array}{c}0.59 \\
(-0.2-2.7)\end{array}$ & $\begin{array}{c}0.77 \\
(-0.5-2.4)\end{array}$ & $\begin{array}{c}0.24 \\
(-0.6-2.0)\end{array}$ & $\begin{array}{c}0.80 \\
(-0.7-1.7)\end{array}$ & $\begin{array}{c}0.55 \\
(-0.5-1.8)\end{array}$ & $\begin{array}{c}0.56 \\
(-1.1-2.0)\end{array}$ & $\begin{array}{c}0.13 \\
(-0.1-1.3)\end{array}$ & $\begin{array}{c}0.52 \\
(-0.5-1.8)\end{array}$ \\
\hline \multicolumn{9}{|l|}{$\begin{array}{l}\text { Children completing each } \\
\text { exercise stage } n\end{array}$} \\
\hline Rest & 11 & 12 & 13 & 11 & 18 & 19 & 13 & 9 \\
\hline $25 \mathrm{~W} \cdot \mathrm{m}^{-2}$ & 11 & 12 & 13 & 11 & 18 & 19 & 13 & 9 \\
\hline $40 \mathrm{~W} \cdot \mathrm{m}^{-2}$ & 11 & 12 & 13 & 11 & 18 & 19 & 13 & 9 \\
\hline $55 \mathrm{~W} \cdot \mathrm{m}^{-2}$ & 11 & 7 & 12 & 10 & 18 & 19 & 13 & 9 \\
\hline $70 \mathrm{~W} \cdot \mathrm{m}^{-2}$ & 4 & 3 & 9 & 2 & 18 & 15 & 11 & 9 \\
\hline $85 \mathrm{~W} \cdot \mathrm{m}^{-2}$ & 1 & & 4 & 1 & 11 & 2 & 11 & 2 \\
\hline $100 \mathrm{~W} \cdot \mathrm{m}^{-2}$ & & & & & 1 & & 7 & \\
\hline $115 \mathrm{~W} \cdot \mathrm{m}^{-2}$ & & & & & & & 3 & \\
\hline $\begin{array}{l}\text { Median maximum workload } \\
\mathrm{W} \cdot \mathrm{m}^{-2}\end{array}$ & 55 & 55 & 70 & 55 & 85 & 70 & 87.5 & 70 \\
\hline $\begin{array}{l}\text { Maximum workload defined as } \\
\text { below normal } \mathrm{W} \cdot \mathrm{m}^{-2}\end{array}$ & $<55$ & $<40$ & $<55$ & $<55$ & $<70$ & 55 & 70 & $<70$ \\
\hline
\end{tabular}

Values are presented as absolute number of subjects (n) or as medians, with ranges in parentheses. M: male; F: female.

out of 312 invited parents gave consent and 106 out of 239 were chosen at random to ensure even representation across the age range for each sex once entry criteria were satisfied. These were: 1) $>7.5$ yrs old, the minimum age which, based on a pilot study, ensured co-operation; 2) $>125 \mathrm{~cm}$ tall, the minimum height for using the exercise bicycle; and 3) no history of recent (3 weeks) acute or significant chronic respiratory or other conditions and not receiving medications.

Twenty three subjects were aged $8.00-10.50$ yrs, 24 were aged 10.51-12.50 yrs, 37 were aged 12.51-14.50 yrs and 22 were aged 14.51-16.9 yrs (table 1).

Children were studied in pairs and walked from school to hospital. All children had been starved for at least $1 \mathrm{~h}$ prior to study. On arrival, their date of birth, race, height (Harpenden height stadiometer; Holtain Ltd, Crymmych, UK), weight (SECA, Birmingham, UK) and two site skinfold measurements (triceps and subscapular; Holtain Ltd, Crymmych, UK) to estimate fat mass [9] were recorded. They then underwent a physical examination to exclude unexpected disease and to assess pubertal status [10]. This was possible in 104 out of 106 subjects, with two boys refusing; 30 were pre-pubertal, 36 in early and 38 in late puberty. Spirometry was used to exclude unexpected airways obstruction (forced expired volume in one second (FEV1) $<80 \%$ of predicted).

\section{Measurements}

The methods for obtaining the physiological measurements were not novel and used inert gas rebreathing. Briefly, rebreathing from a bag containing non-native gases allows equilibrium with the resident lung gas. From this closed system, the rate of uptake of a soluble gas into the pulmonary blood stream is used to calculate the $Q$ 'eff in contact with ventilated alveoli [5, 11-14]; and with knowledge of $f \mathrm{C}$ the effective stroke volume is found. The uptake of oxygen from the same closed system allows measurement of $V^{\prime} \mathrm{O}_{2}$. Using the Fick equation allows the arteriovenous oxygen content difference (AVO) to be calculated from the ratio of $V^{\prime} \mathrm{O}_{2}$ to $Q^{\prime}$ eff. The mixing and dilution of a test insoluble gas with the native lung gas permits calculation of functional residual capacity (FRC), thus being the end of an unforced expiration at the start of a test. The transfer factor of the lung for carbon monoxide (TL,CO) can be used as an estimate of pulmonary capillary blood volume [15-20] from the formula:

$$
1 / T \mathrm{~L}, \mathrm{CO}=1 / \mathrm{Dm}+1 /\left(\theta . V_{\mathrm{c}}\right)
$$

where Dm represents the "resistance" due to the alveolar capillary membrane, $\theta$ is the reaction rate of carbon monoxide with haemoglobin and $V_{\mathrm{c}}$ is the pulmonary capillary blood volume [15-17]. As time = volume/flow then, from the above, the transit time of blood across the respiratory vasculature may be qualitatively estimated from the ratio of $T \mathrm{~L}, \mathrm{CO}$ to $Q^{\prime}$ 'eff [20].

\section{The mass spectrometer and gas mixtures}

The study used an Innovision 2000 mass spectrometer (Innovision, Odense, Denmark) of a very similar specification to that used for the European Space Agency physiological experiments performed aboard the US space 
shuttle in March 1993. It separates gases by their mass: charge ratio and their concentration is proportional to their amplified electrical signal. Comparing the signal with a calibration gas allows concentrations to be calculated. Errors due to changes in gas viscosity, the addition of exhaled water vapour or electrical drift were avoided by ensuring that the total electrical signal represented $100 \%$ of the gas, with the known components correctly apportioned, i.e. automatic total pressure correction.

The calibration gases (tolerance $\pm 2 \%, \mathrm{BOC}, \mathrm{UK}$ ) had a typical make-up of acetylene $0.3 \%$, argon $1 \%$, helium $1 \%$, sulphur hexaflouride $3 \%$, carbon dioxide $5 \%$, oxygen $25 \%$ and balance nitrogen. This tolerance for high concentration gases was further refined by the spectrometer, using the known concentration of oxygen in room air, $20.93 \%$.

The rebreathing test gas had typical contents of $0.3 \%$ carbon monoxide (of stable isotope oxygen-18), $0.3 \%$ acetylene (the soluble gas), 35\% oxygen, 5\% sulphur hexaflouride (the insoluble, inert gas) and balance nitrogen. These cylinders were of absolute grade (zero error; BOC, UK) and all gases were certified of medicinal quality. The ideal rebreathing bag gas volume was found, from a pilot study, to be $40 \%$ of the subject's predicted forced vital capacity. This allowed complete emptying with minimal effort at rest, but was sufficiently large for all stages of exercise.

\section{The pneumatic valve}

A rebreathing manoeuvre requires the accurate detection of the change from expiration to inspiration, in this study at FRC, so that the rebreathing bag can be activated to allow the subject to subsequently breathe by mouth (wearing a nose clip) from a closed system. To avoid the use of inaccurate manually controlled "half-Haldane" valves, the mass spectrometer has a pneumatic valve activated via a calibrated pneumotachograph at the inflection point between expiration and inspiration to close off room air ventilation to the subject and open ventilation to the rebreathing bag. The delay time is $75 \mathrm{~ms}$ and the deadspace is $106 \mathrm{~mL}$. The primary advantage is complete independence from subject co-operation.

\section{Calibration}

The accuracy of the rebreathing bag volume was calibrated daily. Over the entire study, no two consecutive calibrations varied by $>5 \%$. The mass spectrometer was activated at least $12 \mathrm{~h}$ prior to any study to ensure maximum stability. A two-point calibration (zero and calibration gas) was performed three times for each subject and a one point calibration (calibration gas only) $>10$ times. The pneumotachograph zero flow "offset" voltage was calibrated $>3$ times per study.

\section{The exercise protocol}

An electromagnetically braked bicycle (SECA 100, Birmingham, UK) was used for the study as it is less intimidating than a treadmill for young children and workload on such a bicycle is independent of pedal speed over a wide range (4-150 revolutions per minute (rpm)). The protocol consisted of the following steps:

1) The subject arrived, was examined, measured and underwent spirometry.

2) The equipment was explained and the subject underwent two practice rebreathing manoeuvres.

3) The bicycle was adjusted for each subject such that the angle at the knee on full depression of the pedal was approximately $160^{\circ}$ degrees.

4) The child rested silently for $10 \mathrm{~min}$.

5) Whilst the fourth step was in progress, the mass spectrometer underwent a two point calibration. A calibrated pulse oximeter (Nellcor, Hatwood, CA, USA) recording $f \mathrm{C}$ and oxygen saturation was placed over the right supraorbital artery fixed with a bandanna, this site being the least prone to exercise artifact.

6) After resting, the subject performed, whilst seated, five $20 \mathrm{~s}$ rebreathing manoeuvres every 3 min over a 15 min period. Between manoeuvres the subject removed the noseclip and mouthpiece and remained seated. The mass spectrometer had a one point calibration after the third manoeuvre. The pneumotachograph zero offset voltage was checked and adjusted at least twice during this $15 \mathrm{~min}$ period.

7) After the five resting manoeuvres, the subject immediately moved from the chair to the bicycle and was now continuously attached to the mass spectrometer, breathing orally and wearing a noseclip. The subject rested in this position for $4 \mathrm{~min}$. All rebreathing manoeuvres after this point were of $12 \mathrm{~s}$ duration to prevent excess accumulation of carbon dioxide during exercise.

8) The subject, still fully attached to the mass spectrometer, pedalled backwards at "zero" load at "walking pace" speed, to loosen up and get used to the novel feelings engendered by exercising in this manner. During the last $30 \mathrm{~s}$ of this $3 \mathrm{~min}$ stage a further $12 \mathrm{~s}$ rebreathing manoeuvre was performed.

9) The subject then pedalled forwards and was encouraged to maintain a speed of $50-70 \mathrm{rpm}$ signalled by a display. The initial load was $25 \mathrm{~W} \cdot \mathrm{m}^{-2}$. During the last $30 \mathrm{~s}$ of this stage, a $12 \mathrm{~s}$ rebreathing manoeuvre was again performed. Before any rebreathing manoeuvre, a one point (calibration gas) calibration was performed.

10) Following this $3 \mathrm{~min}$ stage, the load was increased every $3 \mathrm{~min}$ by $15 \mathrm{~W} \cdot \mathrm{m}^{-2}$. Again, during the last $30 \mathrm{~s}$ of each stage a rebreathing manoeuvre was performed. These processes were repeated seamlessly without the subject changing their cycling pattern or disconnecting themselves from the noseclip or mouthpiece until exhaustion was reached.

11) Exhaustion was heralded by: 1) the subject whilst pedalling, beginning to labour and rock from side to side; 2 ) the pulse rate was almost always $>190$ beats per minute (bpm); and 3) the pedalling speed would involuntarily speed up then progressively slow. If, on these occurring, the subject had just completed an exercise stage, a question of the form: "Do you think you can carry on for another three minutes" was invariably met with a shake of the head and exercising therefore ceased. If these features suddenly presented early on in a exercise stage, the individual was exhorted to finish that stage, including the rebreathing test, and then stop. Thus, the objective was for all children to stop exercising at the end of a completed 3 min exercise stage. 
12) Upon cessation of exercise, the subject remained seated on the bicycle attached to the mass spectrometer for 9 min undergoing three further $12 \mathrm{~s}$ rebreathing manoeuvres.

13) Nine minutes after completion of exercise, the study terminated. The study lasted, on average $75 \mathrm{~min}$ and was performed only once per child.

\section{Data analysis}

The mass spectrometer software uses algorithms to calculate the core data $\left(Q^{\prime}\right.$ eff, $\left.f \mathrm{C}, V^{\prime} \mathrm{O}_{2}, T \mathrm{~L}, \mathrm{CO}\right)$. However, to minimize error, all 6,921 traces were scrutinized for confounding factors: 1) Was the point of "complete" gaseous mixing between the test gas and resident lung air correctly identified? 2) Was there evidence of pulmonary blood recirculation of the test gas? 3) Was there evidence of any leak, i.e. had the subject inhaled room air around the mouthpiece during rebreathing? 4) Were there other artifacts (e.g. coughing) distorting the validity of the result? All such problems were easily identifiable and corrected. Only six of the 6,921 traces could not be used.

The data was analysed using the Statistical Package for the Social Sciences (SPSS) for Windows V6-0 (SPSS, Chicago, USA). Medians and ranges are used for growth variables. Mean (SD) are quoted in the tables and mean and 95\% confidence intervals in the figures for the cardiopulmonary variables. Extreme values greater than three times the interquartile range were excluded. Forward, step-wise, multiple linear regression was used to determine the significant factors in a variable and was tested both at rest and after completing the $40 \mathrm{~W} \cdot \mathrm{m}^{-2}$ exercise stage. The factors used were gender, surface area ((weight-height/3,600) 0.5$)$, height, weight, age and pubertal stage. Significance was defined as $\mathrm{p}<0.05$.

\section{Results}

Every child performed all the resting manoeuvres, exercised for at least $9 \mathrm{~min}$ and completed the $40 \mathrm{~W} \cdot \mathrm{m}^{-2}$ exercise stage. The number of children completing each stage is shown in table 1. One male refused to complete the recovery part of the study. The growth variables for each sex and age group are shown in table 1. Table 1 also shows the median maximum exercise staged achieved for each subgroup and a completed workload which would be deemed abnormally low.

Physical factors influencing the cardiopulmonary variables during rest and exercise

Surface area, sex and age were the significant $(\mathrm{p}<0.05)$ factors influencing $Q^{\prime}$ eff and in particular $V^{\prime} \mathrm{O}_{2}$ where weight was excluded from the regression in preference to surface area. Surface area and gender only were significant in explaining variability in effective stroke volume and TL,CO per unit lung volume, but age was not. Transit time and AVO were affected by age and sex but not surface area. FRC and TL,CO were significantly influenced by surface area, gender and pubertal stage but not age.

\section{The variability of resting values}

The median coefficient of variation (standard deviation. $100 /$ mean; CV) of the last three resting values for each child (the first two being discarded [5]), was $<12 \%$ for all parameters. The median CV was $7.8 \%$ for $Q$ 'eff and $4.9 \%$ for $T \mathrm{~L}, \mathrm{CO}$. There was no gender effect. The $\mathrm{CV}$ was generally less in children $>12.5 \mathrm{yrs}$; for example the $T \mathrm{~L}, \mathrm{CO}$ median CV was $5.4 \%$ when $<12.5$ yrs and $3.6 \%$ when $>12.5$ yrs (Mann Whitney, $\mathrm{p}=0.003$ ). For FRC, the median $\mathrm{CV}$ was $10.9 \%$ when $<12.5$ yrs and $6.7 \%$ when $>12.5 \mathrm{yrs}$ $(\mathrm{p}=0.002)$.

The mean $(\mathrm{SD})$ for each haemodynamic variable at rest and during exercise are shown in tables $2-11$.

\section{Resting values}

At rest, there were age-dependent effects even after gender and surface area correction, particularly for $V^{\prime} \mathrm{O}_{2}$ (table 2), AVO (table 3) and "transit time" (table 4) where the eldest group of male children had a transit time $60 \%$ longer, despite surface area correction, than the youngest children $(<10.50 \mathrm{yrs})$. Transfer factor (table 5) and FRC (table 6) at rest both showed a sharp rise in late pubertal boys even after surface area correction, which was less evident in girls.

\section{Children undergoing exercise}

Effective pulmonary blood flow at a given surface areacorrected workload showed a weak nonsignificant negative trend with age (table 7). In the latter stages of exercise $\left(\right.$ S $\left.55 \mathrm{~W} \cdot \mathrm{m}^{-2}\right)$ only, there was a marked negative trend in $f \mathrm{C}$ with increasing age with a 27 and $19 \mathrm{bpm}$ difference for boys and girls, respectively, between the oldest and youngest age groups (table 8) although the expected effect on stroke volume was not manifested, perhaps because this value is a ratio and, thus, prone to greater error. During exercise, age effects are also manifested in several variables including $V^{\prime} \mathrm{O}_{2}$ and particularly AVO (table 3) where in both sexes $31 \%$ of the variance is explained by age $(\mathrm{p}<$ $0.001)$.

To determine whether a single linear equation related $V^{\prime} \mathrm{O}_{2}$ to effective pulmonary blood flow, the Fick equation was rewritten as:

$$
Q^{\prime} \text { eff }=(1 / \mathrm{AVO}) \cdot V^{\prime} \mathrm{O}_{2}
$$

i.e., that $1 / \mathrm{AVO}$ represents the slope of the equation. Figure 1 shows a declining 1/AVO with increasing workload signifying a nonlinear relationship.

At a given surface area-corrected workload, the surface area-corrected TL,CO was consistently greater in late puberty compared to prepubertal children in both sexes (table $5)$. However, the transfer constant (TL,CO corrected for lung volume, table 9) did not show such differences. The transit time showed marked age dependence with the oldest children of both sexes showing a longer transit time (table 4). FRC was higher in late- compared to pre-pubertal children after correcting for surface area and did not fall (table 6) with exercise as might be expected (see Discussion). 
Table 2. - Mean and standard deviation (SD) for oxygen consumption for each age group and sex for rest and each stage of exercise

Oxygen consumption $\mathrm{mL} \cdot \mathrm{min}^{-1} \cdot \mathrm{m}^{-2}$

\begin{tabular}{|c|c|c|c|c|c|c|c|c|}
\hline \multirow[b]{2}{*}{ Exercise stage } & \multicolumn{2}{|c|}{ ð10.50 yrs } & \multicolumn{2}{|c|}{$10.51-12.50 \mathrm{yrs}$} & \multicolumn{2}{|c|}{$12.51-14.50 \mathrm{yrs}$} & \multicolumn{2}{|c|}{$>14.50 \mathrm{yrs}$} \\
\hline & $\mathrm{M}$ & $\mathrm{F}$ & $\mathrm{M}$ & $\mathrm{F}$ & $\mathrm{M}$ & $\mathrm{F}$ & $\mathrm{M}$ & $\mathrm{F}$ \\
\hline Rest & $234 \pm 46$ & $188 \pm 26$ & $171 \pm 34$ & $165 \pm 35$ & $182 \pm 54$ & $141 \pm 28$ & $167 \pm 27$ & $165 \pm 40$ \\
\hline $25 \mathrm{~W} \cdot \mathrm{m}^{-2}$ & $612 \pm 108$ & $556 \pm 100$ & $523 \pm 102$ & $532 \pm 93$ & $491 \pm 95$ & $458 \pm 115$ & $592 \pm 209$ & $449 \pm 152$ \\
\hline $40 \mathrm{~W} \cdot \mathrm{m}^{-2}$ & $822 \pm 196$ & $710 \pm 165$ & $666 \pm 153$ & $691 \pm 81$ & $670 \pm 154$ & $598 \pm 132$ & $715 \pm 211$ & $607 \pm 90$ \\
\hline $55 \mathrm{~W} \cdot \mathrm{m}^{-2}$ & $948 \pm 165$ & $887 \pm 172$ & $809 \pm 177$ & $803 \pm 210$ & $779 \pm 147$ & $784 \pm 126$ & $829 \pm 182$ & $787 \pm 102$ \\
\hline $70 \mathrm{~W} \cdot \mathrm{m}^{-2}$ & & $845 \pm 312$ & $952 \pm 155$ & & $952 \pm 155$ & $856 \pm 157$ & $952 \pm 155$ & $937 \pm 135$ \\
\hline $85 \mathrm{~W} \cdot \mathrm{m}^{-2}$ & & & $1075 \pm 161$ & & $1066 \pm 161$ & & $1075 \pm 161$ & \\
\hline $100 \mathrm{~W} \cdot \mathrm{m}^{-2}$ & & & & & $1220 \pm 120$ & & $1220 \pm 120$ & \\
\hline $115 \mathrm{~W} \cdot \mathrm{m}^{-2}$ & & & & & & & $1510 \pm 140$ & \\
\hline
\end{tabular}

For numbers of observations, see table 1. M: male; F: female.

Table 3. - Mean and standard deviation (SD) for arteriovenous oxygen difference for each age group and sex for rest and each stage of exercise

\begin{tabular}{|c|c|c|c|c|c|c|c|c|}
\hline \multirow{3}{*}{$\begin{array}{l}\text { Exercise } \\
\text { stage }\end{array}$} & \multicolumn{8}{|c|}{ Arteriovenous oxygen difference $\mathrm{mL}$} \\
\hline & \multicolumn{2}{|c|}{ ð10.50 yrs } & \multicolumn{2}{|c|}{$10.51-12.50 \mathrm{yrs}$} & \multicolumn{2}{|c|}{$12.51-14.50 \mathrm{yrs}$} & \multicolumn{2}{|c|}{$>14.50 \mathrm{yrs}$} \\
\hline & $\mathrm{M}$ & $\mathrm{F}$ & M & $\mathrm{F}$ & M & $\mathrm{F}$ & M & $\mathrm{F}$ \\
\hline Rest & $62 \pm 7$ & $61 \pm 11$ & $56 \pm 11$ & $54 \pm 14$ & $51 \pm 14 *$ & $46 \pm 8^{\dagger}$ & $52 \pm 10^{+}$ & $51 \pm 11$ 蜶 \\
\hline $25 \mathrm{~W} \cdot \mathrm{m}^{-2}$ & $93 \pm 22$ & $106 \pm 15$ & $92 \pm 22$ & $97 \pm 16$ & $93 \pm 22$ & $83 \pm 14$ & $93 \pm 22$ & $78 \pm 18$ \\
\hline $40 \quad \mathrm{~W} \cdot \mathrm{m}^{-2}$ & $113 \pm 22$ & $119 \pm 19$ & $103 \pm 17$ & $110 \pm 15$ & $99 \pm 20$ & $92 \pm 11$ & $100 \pm 20$ & $91 \pm 14$ \\
\hline $55 \mathrm{~W} \cdot \mathrm{m}^{-2}$ & $123 \pm 14$ & $118 \pm 30$ & $107 \pm 14$ & $115 \pm 21$ & $106 \pm 16$ & $109 \pm 17$ & $113 \pm 21$ & $106 \pm 17$ \\
\hline $70 \mathrm{~W} \cdot \mathrm{m}^{-2}$ & $115 \pm 23$ & $113 \pm 29$ & $124 \pm 14$ & & $120 \pm 17$ & $119 \pm 13$ & $124 \pm 21$ & $115 \pm 18$ \\
\hline $85 \mathrm{~W} \cdot \mathrm{m}^{-2}$ & & & $123 \pm 13$ & & $123 \pm 13$ & & $123 \pm 13$ & \\
\hline $100 \mathrm{~W} \cdot \mathrm{m}^{-2}$ & & & & & & & $135 \pm 13$ & \\
\hline $115 \mathrm{~W} \cdot \mathrm{m}^{-2}$ & & & & & & & $148 \pm 12$ & \\
\hline
\end{tabular}

For numbers of observations, see table $1 .{ }^{*}: \mathrm{p}<0.05$ compared to males $<10.5 \mathrm{yrs}^{*}{ }^{+}: \mathrm{p}<0.05$ compared to males $<10.5 \mathrm{yrs} ;{ }^{\dagger}: \mathrm{p}<0.05$ compared to female $<10.5 \mathrm{yrs}$; ; : $<<0.05$ compared to females $<10.5 \mathrm{yrs}$; M: male; F: female.

Table 4. - Mean and standard deviation (SD) for transit time (transfer factor/effective pulmonary blood flow) for each age group and sex for rest and each stage of exercise

\begin{tabular}{|c|c|c|c|c|c|c|c|c|}
\hline \multirow{3}{*}{$\begin{array}{l}\text { Exercise } \\
\text { stage }\end{array}$} & \multicolumn{8}{|c|}{ Transit time $\mathrm{mmol} \cdot \mathrm{kPa}^{-1} \cdot \mathrm{L}^{-1}$} \\
\hline & \multicolumn{2}{|c|}{ ð10.50 yrs } & \multicolumn{2}{|c|}{$10.51-12.50 \mathrm{yrs}$} & \multicolumn{2}{|c|}{$12.51-14.50 \mathrm{yrs}$} & \multicolumn{2}{|c|}{$>14.50 \mathrm{yrs}$} \\
\hline & $\mathrm{M}$ & $\mathrm{F}$ & $\mathrm{M}$ & $\mathrm{F}$ & $\mathrm{M}$ & $\mathrm{F}$ & $\mathrm{M}$ & $\mathrm{F}$ \\
\hline Rest & $1.01 \pm 0.11$ & $1.04 \pm 0.13$ & $1.22 \pm 0.17 *$ & $1.18 \pm 0.17$ & $1.25 \pm 0.17^{+}$ & $1.20 \pm 0.16$ & $1.56 \pm 0.32^{++, t}$ & $1.33 \pm 0.28$ \\
\hline $25 \mathrm{~W} \cdot \mathrm{m}^{-2}$ & $0.74 \pm 0.10$ & $0.74 \pm 0.10$ & $0.77 \pm 0.15$ & $0.78 \pm 0.10$ & $0.86 \pm 0.20$ & $0.81 \pm 0.11$ & $1.00 \pm 0.15$ & $0.96 \pm 0.26$ \\
\hline $40 \mathrm{~W} \cdot \mathrm{m}^{-2}$ & $0.65 \pm 0.09$ & $0.74 \pm 0.10$ & $0.78 \pm 0.09$ & $0.73 \pm 0.10$ & $0.75 \pm 0.13$ & $0.71 \pm 0.08$ & $0.88 \pm 0.16$ & $0.81 \pm 0.15$ \\
\hline $55 \mathrm{~W} \cdot \mathrm{m}^{-2}$ & $0.68 \pm 0.12$ & $0.69 \pm 0.13$ & $0.67 \pm 0.08$ & $0.69 \pm 0.13$ & $0.70 \pm 0.09$ & $0.69 \pm 0.13$ & $0.84 \pm 0.12$ & $0.69 \pm 0.13$ \\
\hline $70 \mathrm{~W} \cdot \mathrm{m}^{-2}$ & $0.61 \pm 0.13$ & $0.71 \pm 0.13$ & $0.64 \pm 0.0$ & & $0.68 \pm 0.10$ & $0.71 \pm 0.13$ & $0.82 \pm 0.13$ & $0.71 \pm 0.13$ \\
\hline $85 \mathrm{~W} \cdot \mathrm{m}^{-2}$ & & & $0.72 \pm 0.09$ & & $0.72 \pm 0.09$ & & $0.72 \pm 0.09$ & \\
\hline $100 \mathrm{~W} \cdot \mathrm{m}^{-2}$ & & & & & & & $0.73 \pm 0.10$ & \\
\hline $115 \mathrm{~W} \cdot \mathrm{m}^{-2}$ & & & & & & & $0.99 \pm 0.22$ & \\
\hline
\end{tabular}

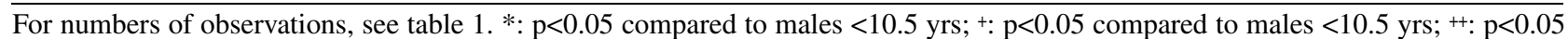
compared to males $<10.5 \mathrm{yrs} ;: \mathrm{p}<0.05$ compared to male $12.51-14.50 \mathrm{yrs} ;: \mathrm{p}<0.05$ compared to females $<10.5 \mathrm{yrs}$; pared to females $<10.5 \mathrm{yrs}$; M: male; F: female.

Table 5. - Mean and standard deviation (SD) for transfer factor for each pubertal stage and sex for rest and each stage of exercise

\begin{tabular}{|c|c|c|c|c|c|c|}
\hline \multirow[b]{3}{*}{ Exercise stage } & \multicolumn{6}{|c|}{ Transfer factor $\mathrm{mmol} \cdot \mathrm{min}^{-1} \cdot \mathrm{kPa} \cdot \mathrm{m}^{-2}$} \\
\hline & \multicolumn{2}{|c|}{ Prepuberty } & \multicolumn{2}{|c|}{ Early puberty (T2-T3) } & \multicolumn{2}{|c|}{ Late puberty (T4-T5) } \\
\hline & $\mathrm{M}$ & $\mathrm{F}$ & $\mathrm{M}$ & $\mathrm{F}$ & $\mathrm{M}$ & $\mathrm{F}$ \\
\hline$\overline{\text { Rest }}$ & $3.73 \pm 0.38$ & $3.37 \pm 0.47$ & $4.14 \pm 0.69$ & $3.53 \pm 0.55$ & $4.93 \pm 0.67 *$ & $3.89 \pm 0.52$ \\
\hline $25 \mathrm{~W} \cdot \mathrm{m}^{-2}$ & $4.82 \pm 0.62$ & $3.92 \pm 0.68$ & $4.74 \pm 0.91$ & $4.32 \pm 0.69$ & $5.43 \pm 1.19$ & $4.75 \pm 0.84$ \\
\hline $40 \mathrm{~W} \cdot \mathrm{m}^{-2}$ & $4.75 \pm 0.88$ & $4.47 \pm 0.83$ & $5.03 \pm 1.08$ & $4.54 \pm 0.57$ & $5.98 \pm 1.18$ & $4.85 \pm 0.84$ \\
\hline $55 \mathrm{~W} \cdot \mathrm{m}^{-2}$ & $5.22 \pm 1.02$ & $5.66 \pm 1.88$ & $5.08 \pm 1.28$ & $4.43 \pm 0.92$ & $5.76 \pm 0.91$ & $5.22 \pm 0.84$ \\
\hline $70 \mathrm{~W} \cdot \mathrm{m}^{-2}$ & $5.28 \pm 1.11$ & $5.27 \pm 2.45$ & $5.21 \pm 1.19$ & $5.40 \pm 1.12$ & $6.07 \pm 1.32$ & $5.37 \pm 1.05$ \\
\hline $85 \mathrm{~W} \cdot \mathrm{m}^{-2}$ & $5.95 \pm 1.49$ & & $5.90 \pm 1.47$ & & $6.71 \pm 1.00$ & $6.23 \pm 0.53$ \\
\hline $100 \mathrm{~W} \cdot \mathrm{m}^{-2}$ & & & & & $6.59 \pm 1.21$ & \\
\hline $115 \mathrm{~W} \cdot \mathrm{m}^{-2}$ & & & & & $10.0 \pm 2.2$ & \\
\hline
\end{tabular}

For numbers of observations, see table $1 .{ }^{*}: \mathrm{p}<0.05$ compared to males in pre- or early puberty. M: male; F: female. 
Table 6. - Mean and standard deviation (sD) for functional residual capacity for each pubertal stage and sex for rest and each stage of exercise

\begin{tabular}{|c|c|c|c|c|c|c|}
\hline \multirow[b]{3}{*}{ Exercise stage } & \multicolumn{6}{|c|}{ Functional residual capacity $\mathrm{L} \cdot \mathrm{m}^{-2}$} \\
\hline & \multicolumn{2}{|c|}{ Prepuberty } & \multicolumn{2}{|c|}{ Early puberty (T2-T3) } & \multicolumn{2}{|c|}{ Late puberty (T4-T5) } \\
\hline & M & $\mathrm{F}$ & $\mathrm{M}$ & $\mathrm{F}$ & $\mathrm{M}$ & $\bar{F}$ \\
\hline Rest & $1.23 \pm 0.08$ & $1.25 \pm 0.30$ & $1.37 \pm 0.26$ & $1.36 \pm 0.19$ & $1.75 \pm 0.21 *$ & $1.52 \pm 0.36$ \\
\hline $25 \mathrm{~W} \cdot \mathrm{m}^{-2}$ & $1.20 \pm 0.30$ & $1.42 \pm 0.42$ & $1.47 \pm 0.38$ & $1.40 \pm 0.25$ & $1.83 \pm 0.32$ & $1.62 \pm 0.33$ \\
\hline $40 \mathrm{~W} \cdot \mathrm{m}^{-2}$ & $1.55 \pm 0.59$ & $1.53 \pm 1.03$ & $1.36 \pm 0.31$ & $1.52 \pm 0.18$ & $1.90 \pm 0.33$ & $1.75 \pm 0.43$ \\
\hline $55 \mathrm{~W} \cdot \mathrm{m}^{-2}$ & $1.50 \pm 0.35$ & $1.63 \pm 0.55$ & $1.39 \pm 0.41$ & $1.56 \pm 0.44$ & $1.93 \pm 0.45$ & $1.80 \pm 0.42$ \\
\hline $70 \mathrm{~W} \cdot \mathrm{m}^{-2}$ & $1.46 \pm 0.33$ & & $1.5 \pm 0.27$ & $1.63 \pm 0.55$ & $1.82 \pm 0.41$ & $1.63 \pm 0.55$ \\
\hline $85 \mathrm{~W} \cdot \mathrm{m}^{-2}$ & & & $1.66 \pm 0.39$ & & $1.98 \pm 0.42$ & \\
\hline $100 \mathrm{~W} \cdot \mathrm{m}^{-2}$ & & & & & $1.97 \pm 0.45$ & \\
\hline $115 \mathrm{~W} \cdot \mathrm{m}^{-2}$ & & & & & $2.76 \pm 0.25$ & \\
\hline
\end{tabular}

*: $\mathrm{p}<0.05$ compared to males in pre- or early puberty. M: male; F: female.

Table 7. - Mean and standard deviation (SD) for effective pulmonary blood flow for each age group and sex for rest and each stage of exercise

\begin{tabular}{|c|c|c|c|c|c|c|c|c|}
\hline \multirow[b]{3}{*}{ Exercise stage } & \multicolumn{8}{|c|}{ Effective pulmonary blood flow $\mathrm{L} \cdot \mathrm{min}^{-1} \cdot \mathrm{m}^{-2}$} \\
\hline & \multicolumn{2}{|c|}{ ð10.50 yrs } & \multicolumn{2}{|c|}{$10.51-12.50 \mathrm{yrs}$} & \multicolumn{2}{|c|}{$12.51-14.50 \mathrm{yrs}$} & \multicolumn{2}{|c|}{$>14.50 \mathrm{yrs}$} \\
\hline & $\mathrm{M}$ & $\mathrm{F}$ & $\mathrm{M}$ & $\mathrm{F}$ & M & $\mathrm{F}$ & $\mathrm{M}$ & $\mathrm{F}$ \\
\hline Rest & $3.80 \pm 0.52$ & $3.16 \pm 0.57$ & $3.08 \pm 0.44^{*+}$ & $3.10 \pm 0.40$ & $3.57 \pm 0.48$ & $3.07 \pm 0.40$ & $3.30 \pm 0.63^{++}$ & $3.24 \pm 0.54$ \\
\hline $25 \mathrm{~W} \cdot \mathrm{m}^{-2}$ & $6.71 \pm 0.55$ & $5.31 \pm 0.88$ & $5.78 \pm 0.98$ & $5.53 \pm 0.78$ & $5.58 \pm 0.98$ & $5.54 \pm 0.95$ & $5.87 \pm 1.24$ & $5.61 \pm 1.33$ \\
\hline $40 \mathrm{~W} \cdot \mathrm{m}^{-2}$ & $7.26 \pm 1.16$ & $6.17 \pm 1.44$ & $6.40 \pm 1.16$ & $6.34 \pm 0.65$ & $6.85 \pm 1.11$ & $6.44 \pm 1.06$ & $7.12 \pm 1.16$ & $6.72 \pm 1.00$ \\
\hline $55 \mathrm{~W} \cdot \mathrm{m}^{-2}$ & $7.62 \pm 1.32$ & $8.25 \pm 3.45$ & $7.56 \pm 1.51$ & $6.95 \pm 0.97$ & $7.42 \pm 1.35$ & $7.26 \pm 1.26$ & $7.31 \pm 0.85$ & $7.48 \pm 1.03$ \\
\hline $70 \mathrm{~W} \cdot \mathrm{m}^{-2}$ & $8.23 \pm 1.36$ & $9.08 \pm 4.47$ & $8.03 \pm 1.47$ & & $8.16 \pm 1.56$ & $7.26 \pm 1.50$ & $7.44 \pm 1.57$ & $8.25 \pm 1.31$ \\
\hline $85 \mathrm{~W} \cdot \mathrm{m}^{-2}$ & & & $8.53 \pm 1.87$ & & $8.92 \pm 1.61$ & & $8.72 \pm 0.93$ & \\
\hline $100 \mathrm{~W} \cdot \mathrm{m}^{-2}$ & & & & & & & $9.06 \pm 0.85$ & \\
\hline $115 \mathrm{~W} \cdot \mathrm{m}^{-2}$ & & & & & & & $10.20 \pm 0.2$ & \\
\hline
\end{tabular}

For numbers of observations, see table $1 .{ }^{*}: \mathrm{p}<0.05$ compared to males $<10.5 \mathrm{yrs}$; ${ }^{+}$p $<0.05$ compared to males $12.51-14.50 \mathrm{yrs}$; ${ }^{++}$. $\mathrm{p}<0.05$ compared to males $<10.5$ yrs. M: male; F: female.

Table 8. - Mean and standard deviation (sD) for cardiac frequency for each age group and sex for rest and each stage of exercise

\begin{tabular}{|c|c|c|c|c|c|c|c|c|}
\hline \multirow[b]{3}{*}{ Exercise stage } & \multicolumn{8}{|c|}{ Cardiac frequency beats $\cdot \mathrm{min}^{-1}$} \\
\hline & \multicolumn{2}{|c|}{ д10.50 yrs } & \multicolumn{2}{|c|}{$10.51-12.50 \mathrm{yrs}$} & \multicolumn{2}{|c|}{$12.51-14.50 \mathrm{yrs}$} & \multicolumn{2}{|c|}{$>14.50 \mathrm{yrs}$} \\
\hline & $\mathrm{M}$ & $\mathrm{F}$ & $\mathrm{M}$ & $\mathrm{F}$ & $\mathrm{M}$ & $\mathrm{F}$ & $\mathrm{M}$ & $\mathrm{F}$ \\
\hline$\overline{\text { Rest }}$ & $87 \pm 7$ & $88 \pm 10$ & $88 \pm 15$ & $88 \pm 11$ & $85 \pm 15$ & $83 \pm 12$ & $81 \pm 10$ & $86 \pm 9$ \\
\hline $25 \mathrm{~W} \cdot \mathrm{m}^{-2}$ & $131 \pm 16$ & $131 \pm 9$ & $117 \pm 16$ & $122 \pm 9$ & $114 \pm 15$ & $121 \pm 14$ & $110 \pm 15$ & $119 \pm 9$ \\
\hline $40 \mathrm{~W} \cdot \mathrm{m}^{-2}$ & $149 \pm 18$ & $156 \pm 13$ & $141 \pm 20$ & $148 \pm 13$ & $131 \pm 16$ & $140 \pm 16$ & $136 \pm 24$ & $137 \pm 12$ \\
\hline $55 \mathrm{~W} \cdot \mathrm{m}^{-2}$ & $174 \pm 20$ & $180 \pm 10$ & $163 \pm 19$ & $172 \pm 13$ & $150 \pm 18$ & $164 \pm 14$ & $146 \pm 16$ & $160 \pm 4$ \\
\hline $70 \mathrm{~W} \cdot \mathrm{m}^{-2}$ & $170 \pm 23$ & $192 \pm 10$ & $179 \pm 14$ & $185 \pm 3$ & $173 \pm 19$ & $181 \pm 13$ & $161 \pm 15$ & $179 \pm 13$ \\
\hline $85 \mathrm{~W} \cdot \mathrm{m}^{-2}$ & & & $190 \pm 11$ & $179 \pm 13$ & $188 \pm 11$ & $189 \pm 12$ & $175 \pm 12$ & $189 \pm 12$ \\
\hline $100 \mathrm{~W} \cdot \mathrm{m}^{-2}$ & & & & & $184 \pm 10$ & & $184 \pm 10$ & \\
\hline $115 \mathrm{~W} \cdot \mathrm{m}^{-2}$ & & & & & & & $188 \pm 4$ & \\
\hline
\end{tabular}

For numbers of observations, see table 1. M: male; F: female.

Table 9. - Mean and standard deviation (SD) for transfer constant for each sex for rest and each stage of exercise

\begin{tabular}{lcc}
\hline \multirow{2}{*}{ Exercise stage } & \multicolumn{2}{c}{ FRC $\mathrm{mmol} \cdot \mathrm{min}^{-1} \cdot \mathrm{kPa}^{-1} \cdot \mathrm{min}^{-1}$} \\
\cline { 2 - 3 } & $\mathrm{M}$ & $\mathrm{F}$ \\
\hline Rest & $2.86 \pm 0.42$ & $2.65 \pm 0.42$ \\
$25 \mathrm{~W} \cdot \mathrm{m}^{-2}$ & $3.35 \pm 1.00$ & $3.07 \pm 0.53$ \\
$40 \mathrm{~W} \cdot \mathrm{m}^{-2}$ & $3.30 \pm 0.70$ & $3.13 \pm 1.10$ \\
$55 \mathrm{~W} \cdot \mathrm{m}^{-2}$ & $3.30 \pm 0.70$ & $3.13 \pm 1.10$ \\
$70 \quad \mathrm{~W} \cdot \mathrm{m}^{-2}$ & $3.45 \pm 0.72$ & $3.25 \pm 0.65$ \\
$85 \mathrm{~W} \cdot \mathrm{m}^{-2}$ & $3.40 \pm 0.39$ & \\
$100 \mathrm{~W} \cdot \mathrm{m}^{-2}$ & $3.32 \pm 0.39$ & \\
$115 \mathrm{~W} \cdot \mathrm{m}^{-2}$ & $3.61 \pm 0.53$ & \\
\hline
\end{tabular}

Note that age was not a significant factor in this variable. For numbers of observations, see table 1. FRC: functional residual capacity; M: male; F: female.
Table 10. - Mean and standard deviation (SD) for effective stroke volume for each sex for rest and each stage of exercise

\begin{tabular}{|c|c|c|}
\hline \multirow[b]{2}{*}{ Exercise stage } & \multicolumn{2}{|c|}{ Effective stroke volume $\mathrm{mL} \cdot$ beat $^{-1} \cdot \mathrm{m}^{-2}$} \\
\hline & M & $\mathrm{F}$ \\
\hline Rest & $41 \pm 9$ & $37 \pm 8$ \\
\hline $25 \quad \mathrm{~W} \cdot \mathrm{m}^{-2}$ & $51 \pm 8$ & $45 \pm 9$ \\
\hline $40 \quad \mathrm{~W} \cdot \mathrm{m}^{-2}$ & $51 \pm 9$ & $46 \pm 11$ \\
\hline $55 \quad \mathrm{~W} \cdot \mathrm{m}^{-2}$ & $48 \pm 10$ & $45 \pm 10$ \\
\hline $70 \mathrm{~W} \cdot \mathrm{m}^{-2}$ & $47 \pm 11$ & $43 \pm 10$ \\
\hline $85 \mathrm{~W} \cdot \mathrm{m}^{-2}$ & $49 \pm 10$ & $48 \pm 6$ \\
\hline $100 \mathrm{~W} \cdot \mathrm{m}^{-2}$ & $49 \pm 9$ & \\
\hline $115 \mathrm{~W} \cdot \mathrm{m}^{-2}$ & $51 \pm 2$ & \\
\hline
\end{tabular}

Note that age was not a significant factor in this variable. For numbers of observations, see table 1. M: male; F: female. 


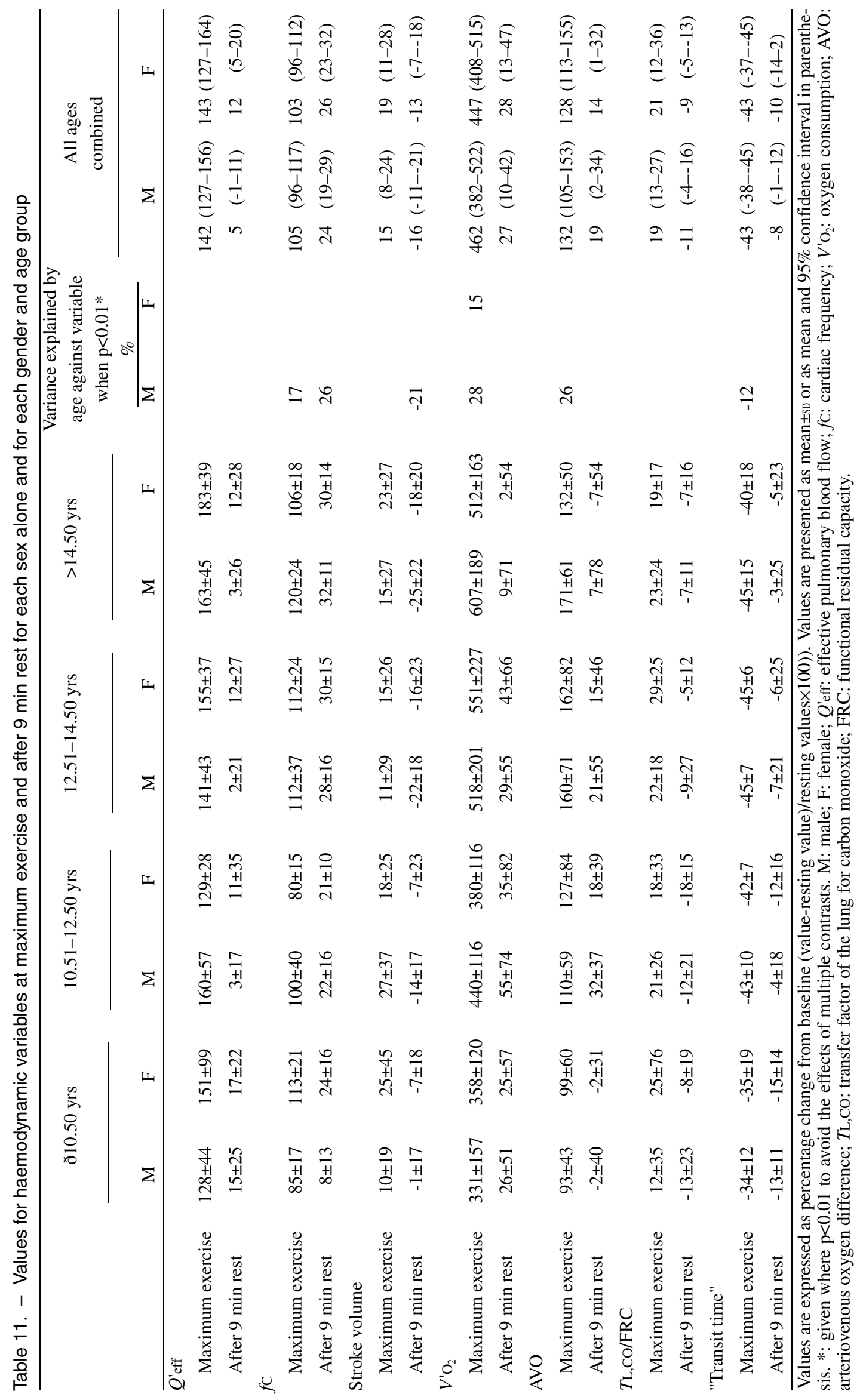




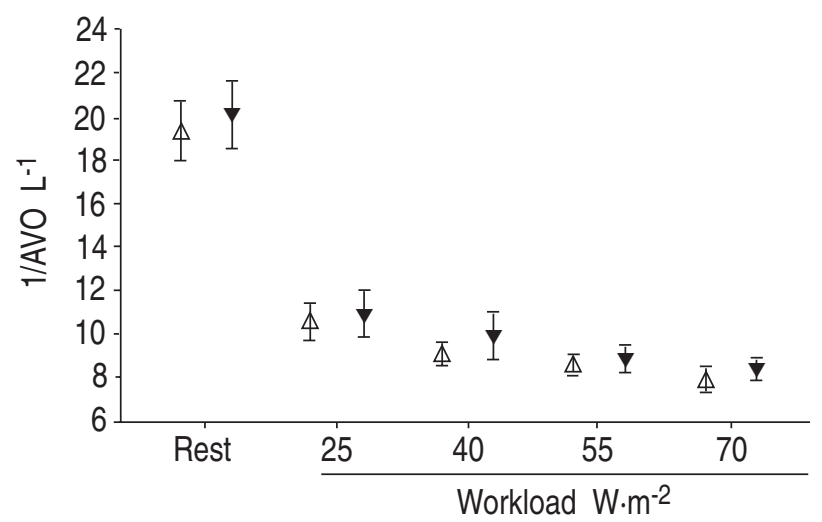

Fig. 1. - The nonlinearity of the gradient (1/AVO) of the Fick equation (effective pulmonary blood flow $=(1 / \mathrm{AVO}) \cdot$ oxygen consumption $)$ as a function of increasing workload for each gender. $\Delta$ : male; $\mathbf{\nabla}$ : female.

Values are presented as mean $\pm 95 \%$ confidence interval.

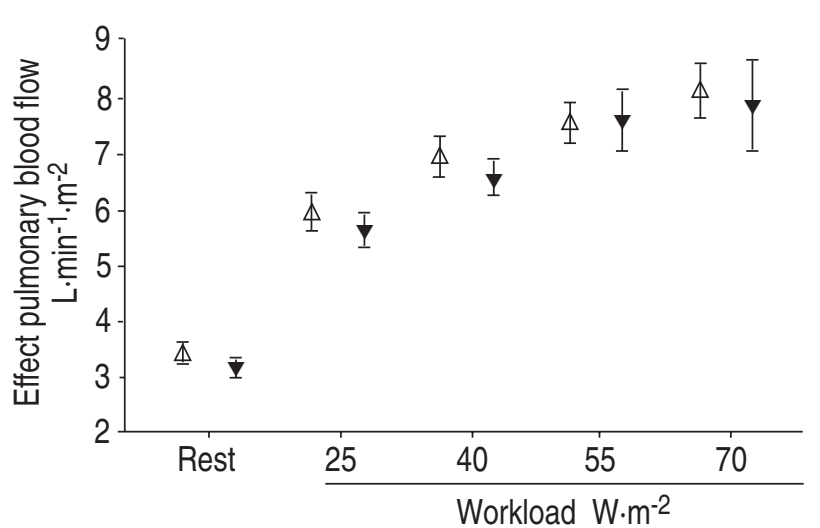

Fig. 2. - Effective pulmonary blood flow (mean $\pm 95 \%$ confidence interval) for males $(\Delta)$ and females $(\boldsymbol{\nabla})$ as a function of workload. Note the gender difference at rest which is lost with increasing exercise.

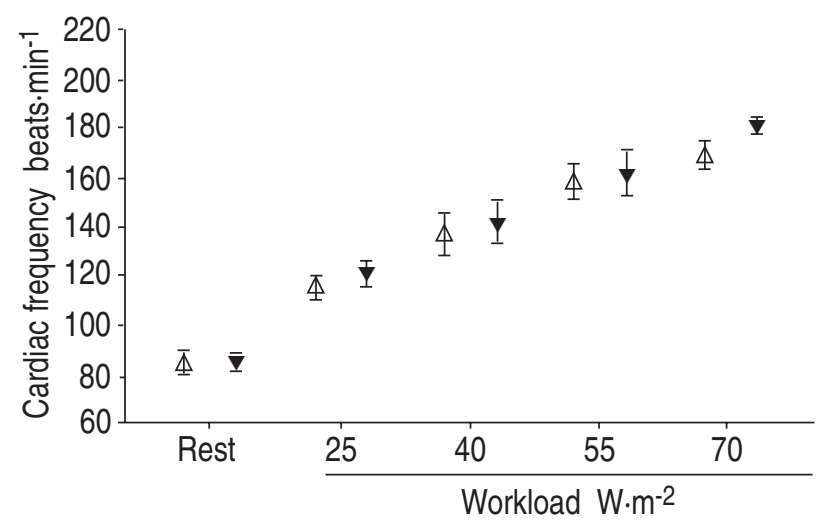

Fig. 3. - Cardiac frequency (mean $\pm 95 \%$ confidence interval) for males $(\Delta)$ and females $(\boldsymbol{\nabla})$ as a function of workload. Note the increased female values compared to males with exercise.

\section{Differences between sexes during rest and exercise}

$Q$ 'eff at rest was significantly lower in girls by some $0.34 \mathrm{~L} \cdot \mathrm{min}^{-1} \cdot \mathrm{m}^{-2}$ at rest (fig. 2) but during exercise, this difference gradually disappeared so that from $55 \mathrm{~W} \cdot \mathrm{m}^{-2}$ onwards, the sexes were similar. This convergence appears largely to be due to the greater increase in $f \mathrm{C}$ with exercise in females compared to males (fig. 3). At rest, $f \mathrm{C}$

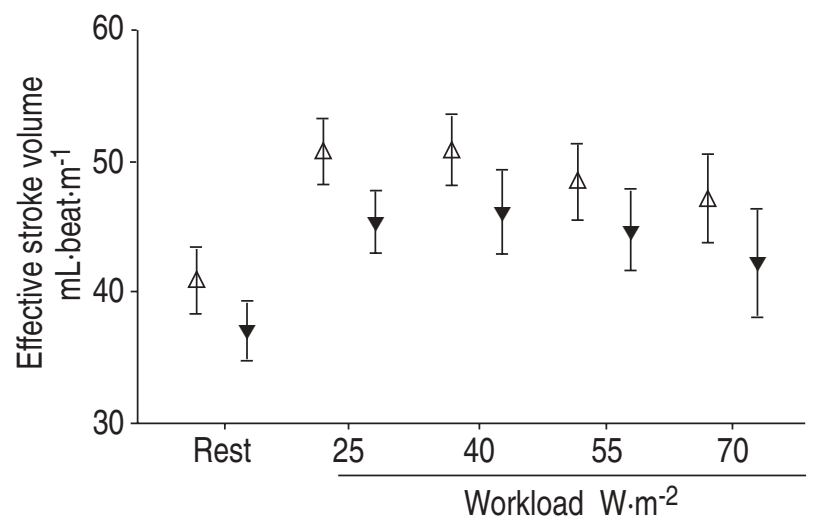

Fig. 4. - Effective stroke volume (mean $\pm 95 \%$ confidence interval) for males $(\Delta)$ and females $(\boldsymbol{\nabla})$ against workload. Note the lower female stroke volume despite surface area correction at all workloads and the decline in stroke volume at high exercise levels.

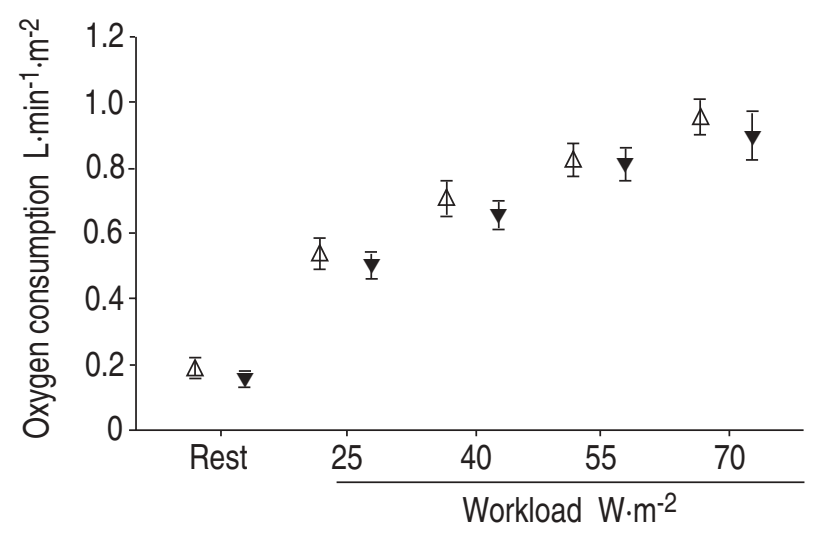

Fig. 5. - Oxygen consumption (mean $\pm 95 \%$ confidence interval) for males $(\Delta)$ and females $(\boldsymbol{\nabla})$ as a function of workload. Note the gender difference at rest, which is lost with increasing exercise.

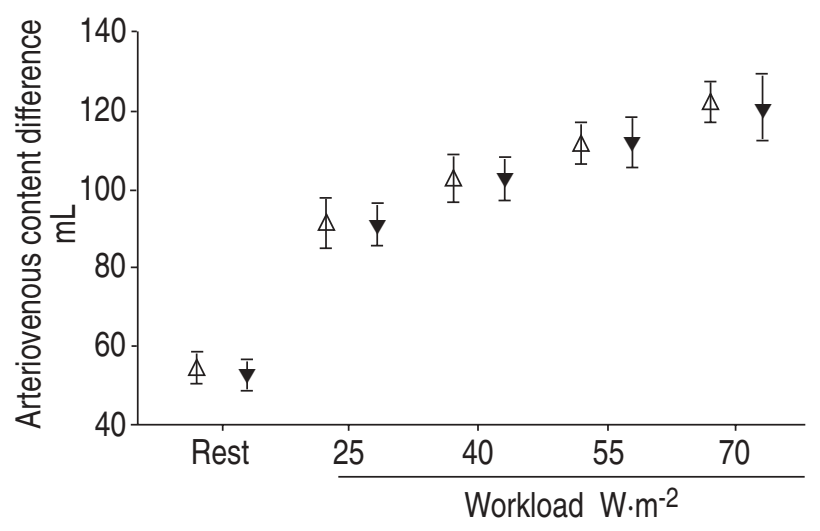

Fig. 6. - Arteriovenous content difference (mean $\pm 95 \%$ confidence interval) for males $(\Delta)$ and females $(\boldsymbol{\nabla})$ as a function of workload.

was the same in both sexes, but by the exercise stages of $55 \mathrm{~W} \cdot \mathrm{m}^{-2}$ and $70 \mathrm{~W} \cdot \mathrm{m}^{-2}$ the $f \mathrm{C}$ values were 9 and $14 \mathrm{bpm}$ greater, respectively, in females $(\mathrm{p}<0.05)$. This increase in $f \mathrm{C}$ appeared to compensate for the significantly lower effective stroke volume present in girls compared to boys during both rest and exercise (fig. 4, table 10). Effective stroke volume was $3.8 \mathrm{~mL} \cdot$ beat $^{-1} \cdot \mathrm{min}^{-2}(8-10 \%)$ less in females at rest and this discrepancy remained throughout exercise (fig. 4).

$V^{\prime} \mathrm{O}_{2}$ (fig. 5) was $22 \mathrm{~mL} \cdot \mathrm{min}^{-1} \cdot \mathrm{m}^{-2}$ lower in females compared to males at rest, but was very similar in the later 
stages of exercise. As this pattern was similar to the $Q^{\prime}$ eff (fig. 2), from the Fick equation, there were no gender differences in the AVO during rest or exercise (fig. 6).

At rest, TL,CO (fig. 7) was $0.71 \mathrm{mmols} \cdot \mathrm{min}^{-1} \cdot \mathrm{kPa} \cdot \mathrm{m}^{-2}$ lower in females than males $(\mathrm{p}<0.01)$. It then approached, but consistently remained significantly below, the value in their male counterparts $\left(e . g\right.$., $0.49 \mathrm{mmol} \cdot \mathrm{min}^{-1} \cdot \mathrm{kPa} \cdot \mathrm{m}^{-2}$ less at $\left.55 \mathrm{~W} \cdot \mathrm{m}^{-2}\right)$ during exercise. This pattern was also seen with FRC (fig. 8) and the transfer constant (fig. 9) tended to mirror this effect. The "transit time" showed a small but significant trend to be shorter in females than males (fig. $10)$.

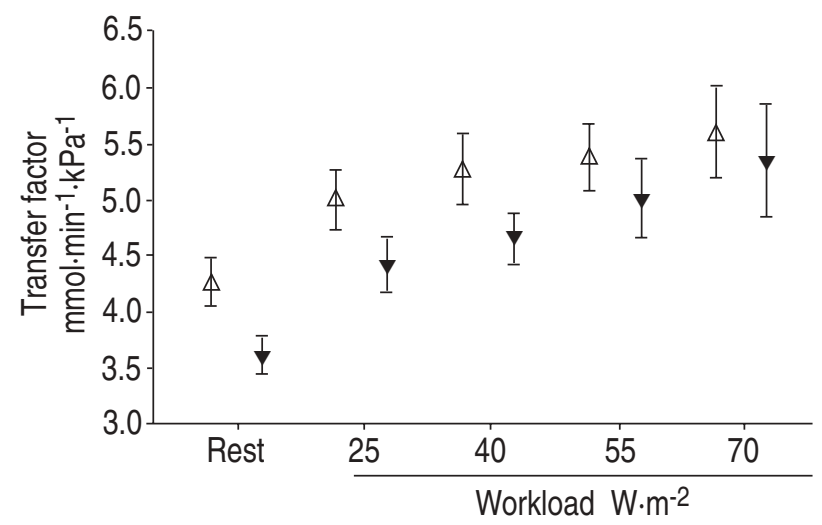

Fig. 7. - Transfer factor (mean $\pm 95 \%$ confidence interval) for males $(\Delta)$ and females $(\boldsymbol{\nabla})$ as a function of workload. Note the gender difference at rest which is partly lost with increasing exercise.

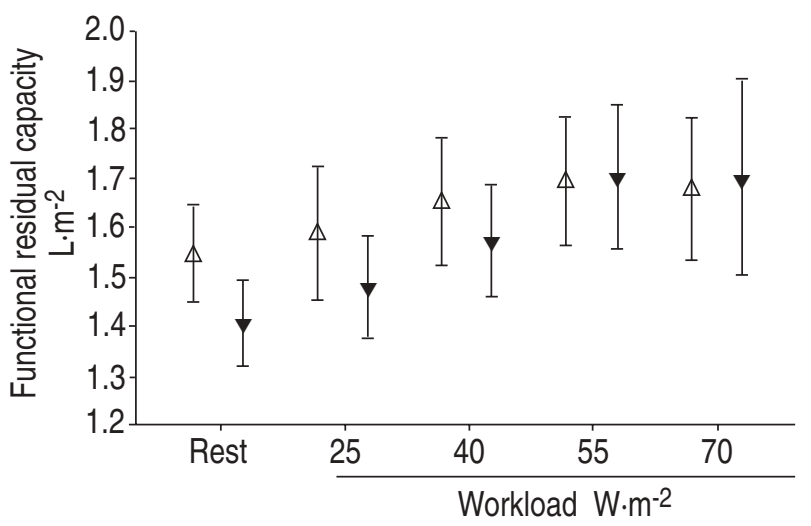

Fig. 8. - Functional residual capacity (mean $\pm 95 \%$ confidence interval) for males $(\Delta)$ and females $(\boldsymbol{\nabla})$ as a function of workload. Note the gender difference at rest which is lost with increasing exercise.

\section{Maximum exercise and recovery}

Using the arbitrary definition of "sufficient exercise" to be an $f \mathrm{C}>170 \mathrm{bpm}$ at "exhaustion" and a respiratory quotient (data not shown) $>1.1,3$ min after maximal exercise [21], 16 out of $23(70 \%)$ children $<10.5$ yrs fulfilled these criteria compared, with 21 out of 23 children aged $>14.5$ yrs, a nonsignificant difference.

To facilitate understanding and to avoid spurious comparisons between age groups and sex, each subject's result at the end of exercise was expressed as a percentage change from their own resting value. All children could,

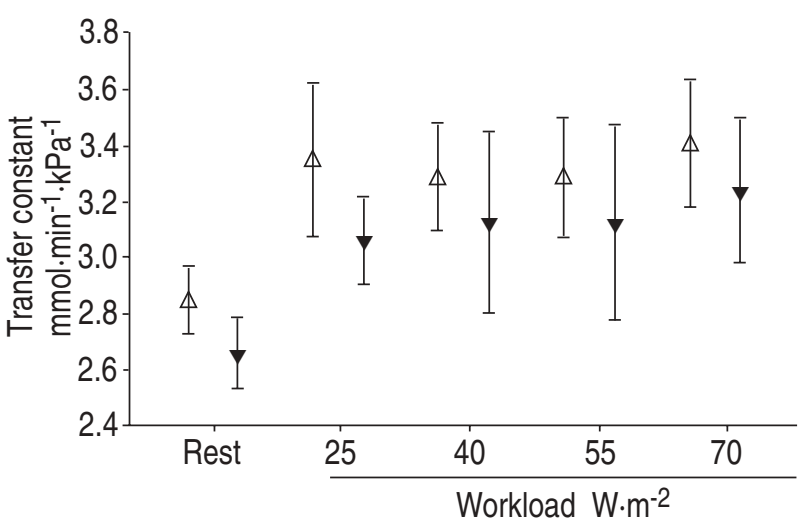

Fig. 9. - Transfer constant (mean $\pm 95 \%$ confidence interval) for males $(\Delta)$ and females $(\boldsymbol{\nabla})$ as a function of workload. Note the gender difference at rest which is lost with increasing exercise.

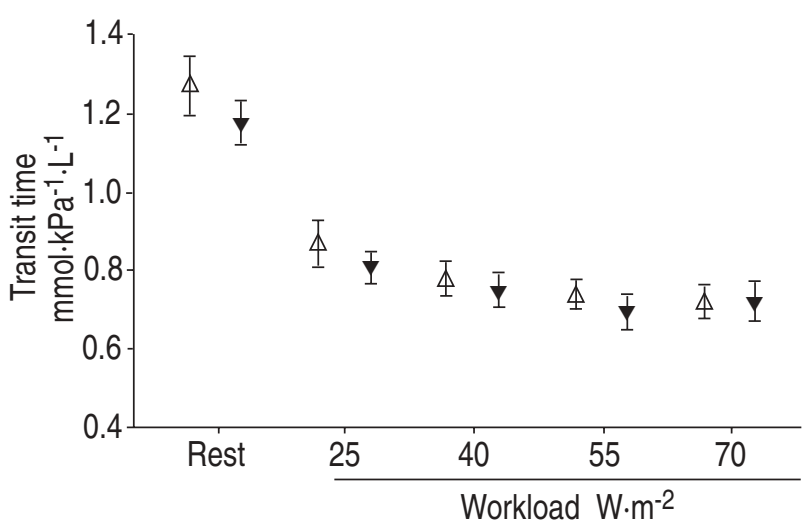

Fig. 10. - Transit time (mean $\pm 95 \%$ confidence interval) for males $(\Delta)$ and females $(\boldsymbol{\nabla})$ as a function of workload.

Table 12. - Values for haemodynamic variables at maximum exercise and after 9 min rest for each sex alone and for each sex and age group

\begin{tabular}{|c|c|c|c|c|c|c|c|c|c|c|}
\hline & \multicolumn{10}{|c|}{ Change from initial resting values $\%$} \\
\hline & \multicolumn{2}{|c|}{ Prepuberty } & \multicolumn{2}{|c|}{ Early puberty } & \multicolumn{2}{|c|}{ Late puberty } & \multicolumn{4}{|c|}{ All stages } \\
\hline & $\mathrm{M}$ & $\mathrm{F}$ & $\mathrm{M}$ & $\mathrm{F}$ & $\mathrm{M}$ & $\mathrm{F}$ & & $\mathrm{M}$ & & $\mathrm{F}$ \\
\hline$\overline{T \mathrm{~L}, \mathrm{CO}}$ & & & & & & & & & & \\
\hline Maximum exercise & $45 \pm 31$ & $46 \pm 51$ & $30 \pm 31$ & $36 \pm 24$ & $38 \pm 32$ & $40 \pm 20$ & 38 & $(29-48)$ & 38 & $(32-50)$ \\
\hline After 9 min rest & $-2 \pm 17$ & $0 \pm 17$ & $-7 \pm 10$ & $-7 \pm 14$ & $-6 \pm 12$ & $6 \pm 14$ & -5 & $(-1--8)$ & 0 & $(-4-5)$ \\
\hline FRC & & & & & & & & & & \\
\hline Maximum exercise & $29 \pm 39$ & $27 \pm 46$ & $10 \pm 35$ & $26 \pm 35$ & $16 \pm 30$ & $11 \pm 24$ & 18 & $(9-29)$ & 19 & $(10-30)$ \\
\hline After 9 min rest & $17 \pm 26$ & $13 \pm 26$ & $3 \pm 20$ & $5 \pm 7$ & $5 \pm 17$ & $12 \pm 19$ & 8 & $(2-17)$ & 9 & $(5-17)$ \\
\hline
\end{tabular}

Values are expressed as percentage change from baseline ((value-resting value)/resting value $\times 100))$. Values are presented as mean $\pm S D$ or as mean and $95 \%$ confidence interval in parenthesis. For definitions of abbreviations, see legend to table 11. 
thus, be compared at different peak workloads to determine their relative capabilities. The mean (SD) for each variable, subdivided by gender and either age or pubertal stage, is shown in tables 11 and 12 together with a mean and $95 \%$ confidence interval for each gender, but with all age groups/pubertal stages combined.

At maximal exercise, the percentage change in $Q$ 'eff above resting was remarkably similar in males (143\%) and females $(142 \%)$. There were no differences in effective stroke volume across the age groups in either sex at maximal exercise. The percent rise in $V^{\prime} \mathrm{O}_{2}$ was higher in the older two age groups at maximal exercise than the younger age groups, in both sexes. Mean maximal $V^{\prime} \mathrm{O}_{2}$ ranged $30-33 \mathrm{~mL} \cdot \mathrm{kg}^{-1} \cdot \mathrm{min}^{-1}$ in males across the age groups, which was significantly higher $(\mathrm{p}<0.001)$ than females, in whom it ranged $23-28 \mathrm{~mL} \cdot \mathrm{kg}^{-1} \cdot \mathrm{min}^{-1}$ across the age groups.

After 9 min rest, $Q$ 'eff was just above resting, but $f \mathrm{C}$ remained some $25 \%$ above baseline in both sexes, such that effective stroke volume was significantly $(12-16 \%)$ below resting $(\mathrm{p}<0.05) . V^{\prime} \mathrm{O}_{2}$ after 9 min rest was $25 \%$ above resting; the AVO (as an estimate of oxygen debt) was, thus, still 14-19\% ( $<<0.05)$ above resting.

The percentage reduction in transit time was equal across the age groups in females at maximal exercise, but was shorter in the older two male age groups compared to the younger two. After 9 min rest, transit time remained $10 \%$ less than baseline. TL,CO increased equally (38\%) in males and females with no differences across the pubertal stages and returned to baseline by $9 \mathrm{~min}$. FRC rose during exercise to some $18 \%$ above resting and remained significantly raised (8-9\%) after 9 minutes rest. This unexpected excess of FRC above resting is considered in the discussion.

Comparing the results for each subject's last (peak) exercise stage and their penultimate one, demonstrated that at peak exercise, $f \mathrm{C}$ and $V^{\prime} \mathrm{O}_{2}$ were at that child's maximum recorded value in $95 \%$ of cases, but in contrast, stroke volume was falling in $91 \%$ (95\% confidence interval 84 $96 \%)$ of cases and the diffusion constant $(K \mathrm{CO})$ was falling in $77 \%(68-85 \%)$ of cases. $Q$ 'eff was falling in $30 \%$ $(20-38 \%)$ of cases and transit time was increasing in $42 \%$ (32-52\%) of cases.

\section{Discussion}

This study provides comprehensive, noninvasive haemodynamic values for healthy children of both sexes over the age range 8-17 yrs using a simple, enjoyable exercise protocol. Values are available at all relevant workloads rather than only their maximum, thus eliminating the quandary of whether an individual's maximum performance was limited by physiological or motivational reasons [22]. This communication establishes SD scores, taking into acount the child's sex, age or pubertal status for all stages of exercise. The study principally found that children at different stages of life adapt to exercise differently, even after allowing for size differences.

Nevertheless some of the measurements still remain surrogate markers for the desired variables, namely $\bar{Q}^{\prime}$, pulmonary capillary number and volume, and pulmonary capillary recruitment during exercise. Instead, due to the requirements for noninvasiveness, the study actually measured, for example, $Q^{\prime}$ eff rather than $\bar{Q}^{\prime}$. This has the ad- vantage of being a functional measure of useful blood flow, but ignores shunts. In healthy children, right to left shunting of blood represents $5 \%$ of the total $\bar{Q}^{\prime}$, decreasing on exercise. Similarly, TL,CO represents a surrogate marker for pulmonary capillary blood volume. Nevertheless this marker is only a composite value representing functioning rather than total pulmonary capillaries. Its derivation also assumes that this volume is a single "well" of haemoglobin, that the flow through it is constant, nonpulsatile and is ventilated by a single alveolus. These ideas are clearly simplistic [19, 20, 23]. FEDERSPIEL [24] add-ressed the idea of uneven flow, whilst newer concepts of fractal geometry render the idea of a single "well" even less tenable [25-27].

The literature contains suggestions for the correction of $T \mathrm{~L}, \mathrm{CO}$ according to the amounts of carboxyhaemoglobin present, the alveolar oxygen tension [28-30] and the varying diffusion rates of the gases [31]. One correction, for example results in a $7 \%$ change in TL,CO for a $2.7 \mathrm{kPa}(20$ $\mathrm{mmHg}$ ) change in alveolar oxygen tension from $16.0 \mathrm{kPa}$ $(120 \mathrm{mmHg})$. Such corrections lend a sense of spurious accuracy to the result and we believe it is more important that comparisons between groups are made under identical conditions so that qualitative differences may be highlighted.

A further ideal of studies such as ours is that the act of measurement ought not to affect the variable in question. A child obliged to breathe orally through a pneumatic valve with a small, but measurable, deadspace is clearly different from the same child riding a bicycle in the street. In this study, $f \mathrm{C}$ and FRC may demonstrate the effects of testing. Although resting $f \mathrm{C}$ showed only minimal age and gender differences, the resting level of $85 \mathrm{bpm}$ measured in this study is some 10-15 bpm higher than would be expected and demonstrates not only anxiety/excitement but the exertion involved in performing a rebreathing manoeuvre to total lung capacity at 40 breaths per minute. The $f \mathrm{C}$ and the $Q$ 'eff may also change due to the increased vigour of breathing [32]; indeed, maximum voluntary ventilation at rest increases $Q$ 'eff by $4.3 \mathrm{~L} \cdot \mathrm{min}^{-1}$ in adults [33] reflecting increased respiratory muscle blood flow. The perturbation in blood flow is less in our study than in others [11], as rebreathing commenced at FRC rather than residual volume.

FRC in this study rose during exercise, when, with the increasing depth of respiration on exertion, it might be expected to fall. One possible explanation for this is the increased airflow resistance that occurs with breathing across a pneumotachograph with an increased amount of saliva on it, despite a drain being present. The pneumotachograph grill cannot be cleaned and recalibrated during exercise as this would involve disconnecting the child from the mouth piece, interrupting the exercise test at a crucial time. Evidence for this explanation may be found when examining FRC 9 min after recovery, where as a group, it remained significantly above resting in both sexes. An alternative explanation is that, unlike adults, airway resistance rises during exercise in the narrower children's airways, increasing FRC.

A strength of this study has been the consistency of the resting measurements, particularly $Q^{\prime}$ eff and $T \mathrm{~L}, \mathrm{CO}$. Resting $Q^{\prime}$ eff measurements in this study accord with those in the literature [5]. There are few data on haemodynamics in children during exercise. Nevertheless, using the same 
flawed [34] statistical methodology as GoDFRey [6] on the current data to construct a $Q^{\prime}$ eff $/ V^{\prime} \mathrm{O}_{2}$ relationship, we obtained similar results. The equation of GODFREY [6] was:

$$
Q^{\prime} \text { eff }\left(\mathrm{L} \cdot \mathrm{min}^{-1}\right)=3.3+6.3 \mathrm{O}_{2}
$$

and that of the present study was:

$$
Q^{\prime} \text { eff }=3.8+5.7 \mathrm{O}_{2}
$$

Thus, at $1 \mathrm{~L} \cdot \mathrm{min}^{-1} V^{\prime} \mathrm{O}_{2}$, the children in the study of GoDFreY [6] had a $Q^{\prime}$ eff of $9.6 \mathrm{~L} \cdot \mathrm{min}^{-1}$ and those in the present study had $9.5 \mathrm{~L} \cdot \mathrm{min}^{-1}$.

Gender clearly influences the physiology of exercise, with females having a lower $Q^{\prime}$ eff at rest but a similar output during exercise, due to their greater increase in $f \mathrm{C}$. One might speculate, therefore, that females with complete heart block may be more compromised when exercising than males, though exercise studies have not addressed this issue [35]. The study by BAR-OR [36] on 10-13 yr old children found that for a given level of $V^{\prime} \mathrm{O}_{2}$, girls had a higher $Q^{\prime}$ and $f \mathrm{C}$, but a lower AVO. Boys had a lower stroke volume at low level exercise, but not at higher level exercise. The current study showed an equal AVO between the sexes, i.e. a similar $Q^{\prime}$ eff for similar $V^{\prime} \mathrm{O}_{2}$, which accords with the data of GODFREY [37]. However, girls in the current study have a lower $V^{\prime} \mathrm{O}_{2}$ per unit work and, thus, have a lower $Q$ 'eff. This may be due to their greater percentage body fat, which has a lower metabolic rate. If $T \mathrm{~L}, \mathrm{CO}$ is indeed a measure of pulmonary capillary blood volume then, at rest, males have a greater volume of functioning pulmonary capillaries than females, but during exercise, as females recruit proportionately more capillaries, their values converge towards their male counterparts (fig. 9).

The present study, together with others $[8,11]$ in adults, though unrecognized at the time, confirms the observation that the relationship of $Q^{\prime}$ eff and $V^{\prime} \mathrm{O}_{2}$ is not linear, as had previously been thought [6]. This is manifested by the nonlinear slope of 1/AVO from the Fick equation (fig. 1). This is not surprising, as an increase in peripheral oxygen extraction/utilization is a predictable part of exercise adaptation.

As this study demonstrates that $f \mathrm{C}$ does not bear a constant relationship to $Q$ 'eff either between the sexes or during exercise, and that $V^{\prime} \mathrm{O}_{2}$ does not bear a constant relationship to $Q^{\prime}$ 'eff, we question the widespread use of $f \mathrm{C}$ and $V^{\prime} \mathrm{O}_{2}$, and derivatives such as the oxygen pulse $\left(V^{\prime} \mathrm{O}_{2} /\right.$ $f \mathrm{C}$ ), as surrogates for $Q^{\prime}$ eff, at least in children. In particular, the oxygen pulse which, from the Fick equation, is assumed to equal the product of the stroke volume and $\mathrm{AVO}$, is potentially highly misleading especially in disease groups where multiple interactions may occur. Even though a crude correlation of oxygen pulse with $Q$ 'eff explained nearly $60 \%$ of the variance in our study in normal children, the range for an individual value was up to $250 \%$ (data not shown). Similarly, in the present study, at an $f \mathrm{C}$ of $160 \mathrm{bpm}, Q^{\prime}$ eff ranged $4-9 \mathrm{~L} \cdot \mathrm{min}^{-1} \cdot \mathrm{m}^{-2}$.

During recovery, we were surprised to find a rapid resolution in resting values of $Q$ 'eff, despite the expected finding of a persistently mildly raised $f$ C. The net result was a significantly lower stroke volume than resting value. How long this situation may continue after 9 min recovery, is unknown. One explanation may be that this study exam- ined $Q^{\prime}$ eff rather than total $\bar{Q}^{\prime}$ and, that the discrepancies found may be due to changes in the shunt fraction within the pulmonary circulation. This may explain the TL,CO and $K \mathrm{CO}$ being below resting values, particularly in males 9 min after maximal exercise, implying a lower pulmonary capillary blood volume taking part in gas exchange, than at rest. Given that FRC was slightly above resting at this stage, there may be a greater proportion of pulmonary alveolar/capillaries units not being perfused. This is not a likely explanation for the nonlinearity of the $Q^{\prime}$ eff $/ V^{\prime} \mathrm{O}_{2}$ relationship since the shunt fraction would need to increase from its assumed resting value of approximately $5 \%$ to $40 \%$ for such a discrepancy to occur, and it is widely believed that shunt fraction declines with exercise.

The present study has also shown that there may be a difference between a variable at peak exercise, and its maximum, after which physiological adaptation to exercise begins to falter. This is most manifest by the observation of a falling effective stroke volume and $\mathrm{KCO}$ at peak exercise. The stroke volume findings may be an in vivo demonstration of Starling's law of the heart; namely that there is a maximum end-diastolic volume/stroke volume relationship after which there is a decline in function. This phenomenon was observed but not commented on in an adult study [38].

In conclusion, reference standards cannot be extrapolated from adults to children and need to take account of size, age, sex and pubertal stage. Standardization of all the results for these factors is crucial if children with disease states are being compared. Without the requirement of relying on the subject's motivation or talent to achieve a true maximum exercise in this study, function can be assessed at submaximal exercise, which is a more realistic test of everyday activity, especially in diseased children.

\section{References}

1. James FW, Blomqvist G, Freed MD, et al. Standards for exercise testing in the paediatric age group (American Heart Association Council on cardiovascular disease in the young). Circulation 1982; 66: 1377A-1397A.

2. Eriksson BO, Grimby G, Saltin B. Cardiac output and arterial blood gases during exercise in pubertal boys. $J$ Appl Physiol 1970; 31: 348-352.

3. Cumming GR. Haemodynamics of supine bicycle exercise in 'normal' children. Am Heart J 1977; 93: 617-622.

4. Lock JE, Einzig S, Moller JH. Haemodynamic responses to exercise in normal children. Am J Cardiol 1978; 41: 1278-1284.

5. Bowyer J, Warner JO, Denison DM. Effective pulmonary blood flow in normal children at rest. Thorax 1988; 43: 972-977.

6. Godfrey S. Exercise Testing in Children - Applications in Health and Disease. London, WB Saunders, 1974.

7. Hermansen L, Ekblom B, Saltin B. Cardiac output during submaximal and maximal treadmill and bicycle exercise. J Appl Physiol 1970; 29: 82-86.

8. Astrand PO, Cuddy TE, Saltin B, Stenberg J. Cardiac output during submaximal and maximal work. $J$ Appl Physiol 1964; 19: 268-274.

9. Tanner JM, Whitehouse RH. Revised standards for triceps and subscapular skinfolds in British children. Arch Dis Child 1975; 50: 142-145.

10. Tanner JM. Growth at Adolescence, 2nd ed. Oxford, Blackwell Scientific Publications, 1962. 
11. Bush A, Busst C, Johnson S, Denison DM. Rebreathing method for the simultaneous measurement of oxygen consumption and effective pulmonary blood flow during exercise. Thorax 1988; 43: 268-275.

12. Cander L, Forster RE. Determination of pulmonary parenchymal tissue volume and pulmonary capillary flow in man. J Appl Physiol 1959; 14: 541-551.

13. Petrini MF, Peterson BT, Hyde RW. Lung tissue volume and blood flow by rebreathing: theory. J Appl Physiol 1978; 44: 795-802.

14. Sackner MA, Greeneltch D, Heiman MS, Epstein S, Atkins N. Diffusing capacity, membrane diffusing capacity, capillary blood volume, pulmonary tissue volume, and cardiac output measured by a rebreathing technique. Am Rev Respir Dis 1975; 111: 157-165.

15. Forster RE, Roughton FJW, Kreuzer F, Briscoe WA. Photocolorimetry determination of rate of uptake of $\mathrm{CO}$ and $\mathrm{O}_{2}$ by reduced human red cell suspensions at $37^{\circ} \mathrm{C}$. $J$ Appl Physiol 1957; 11: 260-268.

16. Forster RE, Roughton FJW, Cander L, Briscoe WA, Kreuzer F. Apparent pulmonary diffusing capacity for CO at varying alveolar $\mathrm{O}_{2}$ tensions. $J$ Appl Physiol 1957; 11: 277-289.

17. Roughton FJW, Forster RE, Cander L. Rate at which carbon monoxide replaces oxygen from combination with human haemoglobin in solution and in the red cell. J Appl Physiol 1957; 11: 269-276.

18. Roughton FJW, Forster RE. Relative importance of diffusion and chemical reaction rates in determining rate of exchange of gases in the human lung with special reference to true diffusing capacity of pulmonary membrane and volume of blood in the lung capillaries. J Appl Physiol 1957; 11: 290-302.

19. Davies NJH. Does the lung work? 4. What does the transfer of carbon monoxide mean? Br J Dis Chest 1982; 76 : 105-124.

20. Scheid P, Piiper J. Diffusion. In: Crystal RG, West JB, eds. The Lung. New York, Raven Press 1991.

21. Rowland TW. Aerobic exercise testing protocols In: Rowland TW, ed. Paediatric Laboratory Exercise Testing. Champaign, IL, USA, Human Kinetics 1993: pp. 19-41.

22. Wilmore JH. Influence of motivation on physical work capacity and performance. J Appl Physiol 1968; 24: 459463.

23. Forster RE. The single-breath carbon monoxide transfer test 25 years on: a reappraisal. 1-physiological considerations. Thorax 1983; 38: 1-4.

24. Federspiel WJ. Pulmonary diffusing capacity: implica- tions of two phase blood flow in capillaries. Respir Physiol 1989; 77: 119-134.

25. Bassingthwaighte J. Physiological heterogeneity: fractals link determinism and randomness in structures and functions. NIPS 1988; 3: 5-10.

26. Glenny RW, Robertson HT. Fractal properties of pulmonary blood flow: characterisation of spatial heterogeneity. J Appl Physiol 1990; 69: 532-545.

27. McNamee JE. Fractal perspectives in pulmonary physiology. J Appl Physiol 1991; 71: 1-8.

28. Kanner RE, Crapo RO. The relationship between alveolar oxygen tension and the single-breath carbon monoxide diffusing capacity. Am Rev Respir Dis 1986; 133: 676678.

29. Frey TM, Crapo RO, Jemsen RL, et al. Adjustment of DLco for varying $\mathrm{COHb}$, and alveolar $\mathrm{PO}_{2}$ using a theoretical adjustment equation. Respir Physiol 1990; 81: 303312.

30. Kendrick AH, Laszlo G. Correction of the single breath carbon monoxide transfer factor in exercise for variations in alveolar pressure. Thorax 1994; 49: 82-84.

31. Jones HA, Lakshminarayan S, Becket JM, Hughes JMB. Comparison of estimates of cardiac output by indicator dilution and freon-22 uptake during gas mixing in dogs. Cardiovasc Res 1991; 25: 523-528.

32. Teichman J, Adaro F, Veicsteinas A, Cerretelli P, Piiper J. Determination of pulmonary blood flow by rebreathing of soluble inert gases. Respiration 1974; 31: 296-309.

33. Anholm JD, Johnson RL, Ramanathan M. Changes in cardiac output during sustained maximal ventilation in humans. J Appl Physiol 1987; 63: 181-187.

34. Matthews JNS, Altman DG, Campbell MJ, Royston P. Analysis of serial measurements in medical research. $\mathrm{Br}$ Med J 1990; 300: 231-235.

35. Alexander T, Friedman DB, Levine BD, Pawelczyk JA, Mitchell JH. Cardiovascular responses during static exercise: Studies in patients with complete heart block and dual chamber pacemakers. Circulation 1994; 89: $1643-$ 1647.

36. Bar-Or O, Shepherd RJ, Allen CL. Cardiac output in 1013 year old boys and girls during submaximal exercise. $J$ Appl Physiol 1971; 30: 219-223.

37. Godfrey S, Davies CTM, Wozniak E, Barnes CA. Cardiorespiratory response to exercise in normal children. Clin Sci 1971; 40: 419-431.

38. Donald KW, Bishop JM, Cumming G, Wade OL. The effect of exercise on the cardiac output and circulatory dynamics of normal subjects. Clin Sci 1955; 14: 37-73. 